\title{
MEDICINA Y POLÍTICA EN FRANCESCO PATRIZI: EL CUERPO DE LA CIUDAD FELIZ
}

\author{
Susana Gómez López \\ Universidad Complutense de Madrid \\ Departamento de Lógica y Filosofía de la Ciencia. Facultad de Filosofía \\ email: susanagl@filos.ucm.es
}

Recibido: 24 julio 2014. Aceptado: 6 noviembre 2014.

Cómo citar este artículo/Citation: Gómez López, Susana (2015), "Medicina y política en Francesco Patrizi: El cuerpo de La Ciudad Feliz", Asclepio 67 (1): p089. doi: http://dx.doi.org/10.3989/asclepio.2015.15

RESUMEN: La ciudad feliz de Francesco Patrizi ha sido casi siempre considerada como una obra perteneciente a la literatura utópica del siglo XVI o como una imagen filosófica de la Venecia real. En este artículo mantengo, en cambio, que Patrizi ideó su Ciudad feliz para defender el modelo político aristocrático expuesto por Aristóteles en su Política y justificarlo con los principios de la medicina platónica que Marsilio Ficino había elaborado en su De vita. Tal intento llevó a Patrizi a describir la ciudad como un cuerpo humano, recurriendo a los principios de la medicina hipocrático-galénica para explicar su funcionamiento y llegando a mantener que el orden de la ciudad es el resultado de la necesidad que tiene el cuerpo cívico de conserva la cantidad y calidad de sus espíritus naturales, vitales y animales.

PALABRAS CLAVE: Patrizi; Política; Medicina; Renacimiento; Filosofía; Aristóteles; Platonismo; Spiritus; Ficino.

\section{MEDICINE AND POLITICS IN FRANCESCO PATRIZI: THE BODY OF THE HAPPY CITY}

ABSTRACT: Besides some disagreements, La città felice of Francesco Patrizi has usually been considered both as a work belonging to the utopian genre of sixteenth century or as a philosophical portrait of the real Venice. In this essay, I maintain, instead, that La città felice was born in Patrizi's mind from his attempt to support the Aristotelian political, aristocratic, order and to justify it according to the principles of the philosophical and Platonic medicine of Marsilio Ficino. Such an attempt led him to describe the polis as a human body, applying the Hippocratic-Galenic system to explain its internal functions and considering that the political order of the city arises from the civic body's needs for maintaining the quantity and quality of natural, vital and animal spiritus.

KEY WORDS: Patrizi; Political thought; Medicine; Renacimiento; Filosofía; Aristotle; Platonism; Spiritus; Ficino.

Copyright: () 2015 CSIC. Este es un artículo de acceso abierto distribuido bajo los términos de la licencia Creative Commons Attribution-Non Commercial (by-nc) Spain 3.0. 
Firmado por Patrizi, en 1553 se publicó en Venecia un volumen que contenía cuatro breves obras: $L a$ città felice; el Dialogo dell'honore, II Barignano; Della diversità dei furori poetici y la Lettura sopra il sonetto del Petrarca. La gola, e 'I sonno, e l'ociose piume. Era la primera obra de quien, de allí a no muchos años, se convertiría en el primer titular de una cátedra extraordinaria de filosofía platónica. Ya para entonces, cuando en 1577 Alfonso II d'Este le ofreció en Ferrara aquella tan privilegiada y deseada posición, Patrizi se había convertido en un férreo detractor de la filosofía aristotélica y en un convencido defensor de la originalidad y supremacía de la filosofía del «divino Platón» ${ }^{1}$. En 1571 había publicado en Venecia el resultado de una de sus grandes empresas, las Discussionum peripateticarum... libri XIII, donde uniendo una ya madura concepción de la historia y una pasión por la lengua griega que, según él, se había despertado en su ánimo desde la más temprana adolescencia, intentaba demostrar a sus lectores que si algo bueno y útil había dicho Aristóteles, lo había tomado de Platón, cuando no de filósofos jonios y sicilianos, que a su vez habían heredado la filosofía mosaica ${ }^{2}$. Las Discusiones eran el fruto maduro de un empeño determinado y tenaz, la pars destruens que Patrizi consideró necesaria para construir tras el derribo una nueva y total filosofía. La edificación del nuevo palacio del saber tomó la forma de la Nova de uniuersis philosophia, aparecida en Ferrara, no sin pocas dificultades, en $1591^{3}$. En aquella voluminosa, densa y compleja obra, Patrizi culminaba el viaje que, con las alas de Platón, había emprendido ya en sus jóvenes años de estudiante en la Universidad de Padua. Sus esfuerzos bien le hicieron merecedor de encontrarse entre los autores insignia de aquel renacimiento del platonismo que desde mediados del siglo XV y hasta bien entrado el XVII inundó el universo del saber. Mas también es cierto que su merecida fama de platónico, unida a esa a veces obstinada, a veces descuidada, costumbre de la historia del pensamiento por presentar a los autores del pasado como si hubiesen nacido y transitado por el mundo con su obra ya preformada desde el nacimiento, ha oscurecido, por no decir ocultado, aspectos del pensamiento de Patrizi difícilmente explicables encerrándolos en los márgenes de la filosofía de Platón. El autor de $L a$ ciudad feliz era un joven de veinticuatro años que apenas había abandonado sus estudios en la efervescente Universidad de Padua, donde entre buenas dosis de descontento por la enseñanza de sus maestros se había sentido seducido por los vientos neoplatónicos, pero distaba aún mucho de ser el Patrizi de la Nova de universis philosophia.

Cada uno de los textos que componen el volumen patriciano de 1553 se enfrenta a cuestiones de índole aparentemente muy diversa, tanto que el lector alejado del tiempo y lugar en el que Patrizi los escribió se puede sentir un tanto atónito y desconcertado al verlos, entre sus manos, encuadernados y formando parte de un proyecto unitario. De la organización del estado a la poesía y su relación con la filosofía, de la reflexión sobre el petrarquismo al discurso sobre la virtud y el honor. Mas apenas vamos concentrando la mirada en ese torbellino cultural que fue la República Véneta en el siglo XVI, percibimos la corriente de fondo que hacía que el vínculo entre todos aquellos temas fuese, en aquellos años, de tremenda actualidad. Tanto que se ha llegado a decir de los textos del volumen de 1553 que no fueron sino "el secuaz ejercicio de un joven estudioso que estaba tratando de abrirse camino siguiendo los senderos que estaban de moda ${ }^{4}$. Mas también es cierto que en aquellas páginas se encontraban ya apuntados, como si de un boceto se tratase, muchos de los que de allí a pocos años se convertirían en los principales nudos del pensamiento de Patrizi. Y se encontraba bosquejado, sobre todo, su talante filosófico, su particular modo de abordar el estudio de la naturaleza, del alma, del ser humano, de la historia o de la poesía. Cada uno de los escritos de la obra tiene una cierta independencia y brota de unas propuestas filosóficas que, haciendo un ejercicio un tanto detectivesco, se pueden reconstruir. El lector puede llegar a una cierta página, detenerse y formarse una idea de los propósitos intelectuales de Patrizi. Sin embargo, sería una percepción un tanto engañosa, pues son precisamente los vínculos que subterráneamente el autor teje entre un texto y otro los que les hacen cobrar un nuevo sentido. En otras palabras, bajo esa aparente suma de textos inconexos, de exaltaciones y apologías ora platónicas, ora aristotélicas, ora petrarquistas, hay un plan general, un proyecto con una coherencia interna.

\section{LA CIUDAD FELIZ, O LA ANATOMÍA DEL ESTADO}

No es fácil saber qué es La ciudad feliz, ni adivinar cuál era su propósito, más allá del intento de su autor de presentarse a la república de las letras. Quizá lo más inmediato, y así se ha hecho muchas veces, sea considerar aquella breve obra como una utopía, escrita en un momento de especial florecimiento de tal género literario. No podemos excluir que el furor que la época sintió por la construcción imaginaria de estados y ciudades perfectas y virtuosas hiciese mella en Patrizi, como sucedió a muchos de quienes participaban de la vida cultural véneta. De hecho, en 1548 se había publicado en Venecia, despertando elogios y aplausos, la traducción italiana de la famosa Utopía de Tomás Moro (1516). Y entre 1552 y 1553, coincidiendo con la publicación de La ciudad feliz, Anton Francesco Doni (1513-1574), que había conocido a Moro y colaborado con Ortensio Lando en la preparación de la traducción italiana de Utopía, ofrecía al público su retrato de la ciudad utópica en I Mondi ${ }^{5}$. Pero la ciudad a la que se refería Patrizi no tenía los rasgos de las ciudades 
imaginarias de las utopías, no era una isla lejana, ni un recinto amurallado, ni una urbe construida sobre suelo lunar, ni tenía cien puertas, ni forma de estrella. No se describían ni sus edificios, ni sus templos, ni los lenguajes de sus ciudadanos. No se ofrecía al lector como una alternativa posible y prometedora a lo ya existente, como un punto de fuga hacia el cual encaminar costumbres, educación y formas de gobierno. O al menos aparentemente no lo hacía, pues cuando el lector llega a su última página y comienza la lectura del texto sobre el furor poético, empieza, como veremos, a entender hacia dónde quería volar Patrizi con las alas de las que hablaba ya en la dedicatoria. Aun así La ciudad feliz de Patrizi se asemejaba más a un discurso legitimador de algo ya existente. La propia ciudad de Venecia, han dicho algunos de quienes han negado a la obrita de Patrizi el carácter utópico ${ }^{6}$.

En el fondo, se trate o no de una utopía, lo cierto es que, como éstas, nacía de un clima de urgente necesidad por replantearse la estructura del estado y la organización de la sociedad civil. Ya desde finales del siglo XIV los humanistas habían empezado a enfrentarse a los problemas que se derivaban de la transformación de los estados y las relativas formas de gobierno y en ese clima inquieto la Política de Aristóteles despertó un gran interés entre gobernantes, políticos e intelectuales ${ }^{7}$. La traducción realizada por Leonardo Bruni en 1438 fue el inicio de una oleada de ediciones del texto aristotélico que inundó Europa. A lo largo del siglo XVI, solo en la traducción de Bruni se hicieron cincuenta ediciones de la Política, lo cual se dejó sentir rápidamente en las propuestas acerca de las características que debían tener la ciudad y el estado ${ }^{8}$. La obra de referencia en la época sobre la estructura de la ciudad, el De re aedificatoria (1452) de Leon Battista Alberti, consideraba que la forma de la urbe y la arquitectura de sus edificios debían corresponder al modelo político y que tanto este último como la ciudad debían estar al servicio del fin último del hombre: la felicidad. Los humanistas insistieron en la importancia de desarrollar el proyecto aristotélico de fundar una política sobre una reflexión ética, sobre una filosofía de las virtudes humanas y civiles, de tal modo que, como para el propio Aristóteles, la Política había de ser concebida como una aplicación a la ciudad-estado del análisis sobre la virtud expresada en la Ética a Nicómaco. ${ }^{9}$ La felicidad, la eudaimonia, es, para Aristóteles, el bien supremo del hombre individual, pero lo es también de su asociación con los demás hombres, es decir, de la ciudad. Y si en la ética nicomaquea la felicidad era el resultado de la vida virtuosa, en clave política la ciudad será feliz si su estructura y sus formas de gobierno están fundadas en la virtud.

El estudio de la ética había ido ganando cada vez más terreno y prestigio en las universidades italianas, tradicionalmente poco dadas al estudio de la teología. A principios del siglo XVI la Etica a Nicómaco y la Política de Aristóteles y la República de Platón se exponían y discutían en las aulas tanto como en las academias literarias y las cortes principescas. Francesco Robortello, profesor de Patrizi en Padua, enseñaba filosofía moral y en 1552, un año antes de la publicación de $L a$ ciudad feliz, había dado a la imprenta en Venecia una Disputatio in libros politicos Aristotelis, donde reclamaba para el filósofo la tarea de enseñar la política y donde defendía un programa político claramente inspirado por la idea aristotélica de que la organización de la ciudad ha de tener como objetivo máximo la felicidad, un bien que solo se puede conseguir practicando las virtudes contemplativas y especulativas. Es curioso observar cómo a distancia de bastantes años, cuando Patrizi recordará en su carta autobiográfica a Baccio Valori sus años de estudiante en Padua, no mencionará a Robortello. Casi diríase obsesionado con retratarse como un autodidacta, solo nombraba a los profesores que había escuchado y no le habían gustado. Mencionar a Robortello habría desvelado su treta, dejando al descubierto que ni tan original ni tan pretendidamente autodidacta era ${ }^{10}$.

La adhesión a los principios de la ética y la política aristotélicas no planteó grandes problemas a quienes a partir del siglo XV apostaron por seguir la senda de Platón. La salida a la aparente contradicción consistió, en gran medida, en acogerse a la idea de la única verdad: si Platón y Aristóteles en su República y en su Política, respectivamente, parecían contradecirse, las contradicciones debían ser solo cuestión de palabras, de interpretaciones, pero ajenas al fondo de la cuestión ${ }^{11}$. Se imponía argumentar la conciliación y fue esta necesidad la que abrió la puerta a interesantes mezclas de temas platónicos y aristotélicos, a intersecciones entre la platónica idea del Bien y la perfección, la teoría del conocimiento, la derivación de todas las cosas del mundo de la divinidad, de los cielos y los astros, y el despliegue, la aristotélica práctica de las virtudes morales y políticas en el ámbito de la ciudad $^{12}$. El volumen que Patrizi dio a la imprenta en 1553 es una elocuente demostración de aquel necesario, y para muchos deseado, proyecto de conciliación entre una filosofía política defensora de un estado aristocrático y un entramado de temas platónicos que van de la poética a la cosmología, de la filosofía natural a la poética de la historia o a la retórica. En este sentido, la obra del Chersino demostraba un talante muy afín al de los intelectuales vénetos que en tiempos del doge Andrea Gritti (1455-1538, en el poder desde 1523 hasta su muerte) empezaron a reflexionar sobre la posibilidad de erigir la razón política de la oligarquía véneta sobre una metafísica platónica ${ }^{13}$.

Ya en la dedicatoria de La ciudad feliz, dirigida a los hermanos Della Rovere, Urbano Vigerio y Girola- 
$\mathrm{mo}^{14}$, Patrizi expresaba claramente cuál era su objetivo: "hacer menos duro el camino de ascenso a ese monte en cuya cima la felicidad ha situado el paraíso de sus delicias, al cual poquísimos hombres podrán llegar» (Città felice, p. 3r). Ofrecía su escrito como si fuesen unas alas de Dédalo "con las cuales elevarse en vuelo siguiendo al divino Platón», que descansaba ya en aquel paraíso de beatitud ${ }^{15}$. Pero a Patrizi no le interesaba la felicidad de las almas desprendidas de sus cuerpos, la felicidad de los muertos, sino la que se podía alcanzar en la vida terrena. El hombre de carne y hueso, de naturaleza corruptible e imperfecta, no tiene garantizada en este mundo la felicidad, pero vagamente la recuerda. Con un tono afín al de textos herméticos y emanantistas, Patrizi afirmaba que «del profundísimo abismo por la bondad de Dios surgieron en el principio todas las cosas, que a este bajo mundo derivaron». El abismo de las aguas supracelestes del que todo fluía y emanaba no era sino el platónico mundo de las Ideas, el paraíso de la abundancia y la perfección (Città felice, p. 4v) ${ }^{16}$. Recordar aquel originario estado de plenitud y no saber cómo recuperarlo era para el hombre terreno un tormento. La oferta de Patrizi era aliviarlo mostrando el camino «para encontrar ese manantial y edificar una ciudad sobre la cual continuamente caiga y con sus felicísimas aguas bañe» (Città felice, p. 4v) ${ }^{17}$. La ciudad feliz era solo el primer paso del duro y difícil camino de ascenso a aquellas misteriosas alturas.

Mas no nos dejemos embaucar por la reverencia a Platón, pues el propio Patrizi reconocía de qué estaban hechas aquellas alas: "de la disposición y estatutos que Aristóteles piensa que ha de tener una ciudad que aspire a ser feliz» (Città felice, p. 2r). Había seguido punto por punto al Estagirita, permitiéndose, si acaso, dejar algún espacio a su propio ingenio para correr libremente. Uno de esos espacios era precisamente su intento de síntesis entre la ética y la política aristotélicas y algunos elementos de la filosofía platónica, lo cual, como ya hemos visto, no era nada particularmente extraño ni escandaloso en los ambientes intelectuales en los que Patrizi se movía. Otro espacio de libertad, en este caso mucho más original e interesante, era su explicación en clave naturalista de la organización y estructura que ha de tener la ciudad para ser feliz.

La felicidad es el sumo bien, la máxima aspiración del hombre y, «como sabiamente la describió Aristóteles [ ], una operación según la virtud más perfecta, sin impedimento, a lo largo de toda la vida» (Città felice, p. 5r). Se trataba de la concepción de la felicidad que Aristóteles había desplegado en su Ética a Nicómaco, donde criticaba sin ambages el modo en que Platón había entendido el sumo bien, prefiriendo, en cambio, una interpretación práctica, relacional, del bien y la felicidad ${ }^{18}$. Ninguno de los dos eran, para Aristóteles, puras ideas, sino el resultado de una forma de actuar. Una cuestión, en fin, práctica. Y si la felicidad es una praxis, una operación, una forma de actuar, ésta solo se puede realizar en vida. Los muertos no actúan. Cierto que Aristóteles había hecho una clasificación de los bienes atendiendo a si solo pertenecían al alma o al cuerpo o al gobierno o influencia que el uno tiene sobre el otro, pero reconocía claramente que la felicidad, por mucho que sea una forma de actuar del alma, necesita de los bienes exteriores y de los instrumentos para alcanzarlos. Además, y este aspecto resulta esencial para entender la reflexión de Patrizi, la felicidad es cuestión de una vida entera, no de momentos felices o afortunados; "una golondrina no hace verano», que se leía en la Ética a Nicómaco. Es decir, solo se puede alcanzar la felicidad mientras se está vivo, y sólo se está vivo mientras alma y cuerpo se mantienen unidos. En palabras de Patrizi:

En la tercera parte de la definición [de felicidad según Aristóteles], que es aquella que se refiere a la de una vida entera, se comprende el séptimo grado, común al cuerpo y al alma; pues solamente puede llegar a ser feliz aquel cuyo hilo de la vida se prolonga por todo el espacio del curso del humano vivir, por lo cual, si en su mitad fuese truncado, no podría él en modo alguno llegar al manantial del que hemos hablado (Città felice, p. 5v) ${ }^{19}$.

El hombre está compuesto de un alma inmortal, incorruptible y autosuficiente y de un cuerpo material, corruptible y perenemente necesitado de un alma que lo dirija y de bienes materiales que lo mantengan. La vida, escribía Patrizi no sin ocultar su acuerdo con Platón, Aristóteles y todos los médicos y filósofos que de ello habían tratado, era la unión del alma y el cuerpo: "tanto tiempo vive el hombre, como el alma permanece unida al cuerpo, y el alma tanto se queda con él, como dura el vínculo que los mantiene unidos, y este vínculo son los espíritus, llamados por los mencionados filósofos y médicos, primeros instrumentos del alma» (Città felice, pp. 6r-v; el subrayado es mío).

Es este el núcleo de la propuesta de Patrizi, lo que hace de este aparente resumen de la política aristotélica un texto original y merecedor de atención, una reflexión ético política pero también una demostración del interés por la medicina y la filosofía natural. La Città felice se convierte, gracias al concepto de "espíritu» como vínculo entre el alma y el cuerpo, y por tanto garante de la vida, en una naturalización del orden y el buen gobierno de la ciudad, que son los que permiten alcanzar la felicidad. Aristóteles, en el libro I de la Política, había afirmado que el origen de la ciudad es una cuestión natural íntimamente ligada a la insuficiencia del hombre para autoabastecerse y mantenerse con vida (Política I 2, 1252b-1253a). Estaba en esto de acuerdo con Platón, que en el Libro 
Il de la República mantenía que el estado surge de la incapacidad del individuo para cubrir sus necesidades; de ellas se deriva el ejercicio de los diferentes oficios y cometidos en la sociedad, del de los labradores al de los artesanos o al de las milicias (República, II, 369a-376a). Empieza el hombre por aparearse, decía Aristóteles, y procreando forma familias que a su vez se agrupan formando pueblos. La misma insuficiencia del individuo, sumada a las diferencias de la naturaleza de cada uno de ellos, hace que siervos y padrones se necesiten mutuamente, estableciéndose una relación simbiótica. Pero Aristóteles no había ido más allá en su afirmación del origen natural de la ciudad, dejando abierta la pregunta sobre el significado que atribuía al concepto de "naturaleza» cuando se refería a la organización política. Parecía ser una idea contradictoria con la definición de lo natural que había establecido en su Física, donde lo natural es aquello que tiene en si mismo la causa de ser lo que es, en oposición a lo artificial, cuya causa es externa. $Y$ parecía ser contradictorio porque a lo largo de la Política se hacía patente que era el gobernante, el amo y no los siervos, quien organizaba y daba forma a la ciudad. En suma, la ciudad estado, por mucho que tuviese su origen en una necesidad natural de los seres humanos, parecía más una máquina creada que un organismo "naturalmente» generado. El desarrollo que Patrizi hace del naturalismo político aristotélico y de la sugerida analogía entre cuerpo y ciudad pretende dar respuesta a esta aparente contradicción: en un estado aristocrático los magistrados organizan la ciudad del mismo modo que las facultades mentales gobiernan al cuerpo, y no por ello la relación cuerpoconocimiento se dice artificial ${ }^{20}$.

La idea central de La ciudad feliz es que toda la organización de la ciudad ha de estar al servicio de la generación y el buen mantenimiento de los espíritus. Queda bien claro desde el principio que los espíritus de los que habla Patrizi son los mismos a los que se refería toda la tradición médica hipocrático-galénica, la misma que había estudiado en las aulas de la Facultad de Artes de Padua (Città felice, pp. 6r-v). Lo cual no significa, como veremos más adelante, que Ficino quisiese limitar su concepción de los espíritus al puro tratamiento fisiológico, médico. En consonancia con una concepción tripartita de las potencias del alma - animal, vital y natural - los médicos antiguos, desde Herófilo y Erasístrato, habían mantenido que cada una de aquellas potencias tenía sede en una parte del cuerpo. La potencia animal se encontraba en el cerebro, la vital en el corazón y la natural en el hígado, si se refería a la nutritiva, o en los testículos, si relativa a la potencia generativa. Galeno, recogiendo las ideas de los hipocráticos, dio forma a la descripción de un organismo regulado por espíritus de diferentes tipos, los cuales se originan en cada una de las tres partes del cuerpo y se corresponden, a su vez, con las tres potencias del alma. Los alimentos ingeridos llegan al estómago y de allí pasan al hígado, donde a partir de un proceso de refinamiento del quilo se generan los espíritus naturales. Estos últimos, mezclados con la sangre venosa, pasan del hígado al corazón, donde al mezclarse con el aire inspirado se generan los espíritus vitales. Finalmente, los finísimos espíritus vitales pasan al cerebro, donde se produce un ulterior proceso de refinamiento de la sangre arterial que da lugar al grado más sutil del espíritu, los espíritus animales, de los cuales dependen las funciones psíquicas. Estos espíritus, como los otros dos, son distribuidos también por todas las partes del cuerpo, en este caso a través de los nervios, y gracias a ellos se explican las sensaciones y las capacidades motoras ${ }^{21}$.

Lo primero, por tanto, que necesita la ciudad para aspirar a la felicidad es generar y mantener en buen estado los espíritus naturales. O en otras palabras, necesita que los ciudadanos se alimenten: «tenga por tanto comida y bebida la ciudad si desea vivir y ser feliz» (Città felice, p. 6v). Y si los alimentos más básicos y esenciales son aquellos que nacen de la tierra, «tendrá la ciudad necesidad de campesinos, de pastores y de agricultura», que habrán de ser hombres robustos y capaces de soportar el duro trabajo. Pero sobre todo habrán de ser sumisos, tímidos, «siervos por naturaleza», como lo habrán de ser también todos aquellos trabajadores manuales, artesanos, molineros, carniceros, panaderos, cocineros, albañiles, carpinteros, herreros o picapedreros. Todos aquellos, en fin, cuya misión en la ciudad es la generación de los espíritus naturales. El escalafón más bajo de la jerarquía de la ciudad, del mismo modo que el estómago y el hígado son los lugares del cuerpo encargados de la generación de los espíritus más burdos (Città felice, pp. $6 v-7 v)^{22}$. La analogía entre las partes de la ciudad y las partes y funciones del cuerpo permitía a Patrizi dar una justificación en clave naturalista del status servil de los trabajadores manuales, un tema en el que tanto había insistido Aristóteles en la Política. Si la felicidad es una práctica de la virtud, al trabajador manual le está vedada por principio, «pues no es posible que se ocupe de las cosas de la virtud el que lleva una vida de trabajador o jornalero» ${ }^{23}$.

Así pues, una vez aclarada la necesidad de los serviles trabajadores manuales para la generación de los espíritus naturales, se imponía, según Patrizi, conservar estos últimos e impedir que se corrompiesen. Y de esta conservación serán ya responsables los auténticos ciudadanos libres: los comerciantes y mercaderes, los guerreros de los ejércitos y los magistrados, a los que habrán de sumarse los sacerdotes, cuya misión en la conservación de los espíritus queda, en la Ciudad feliz, un tanto relegada ${ }^{24}$. Mas antes de atribuir competencias en la conservación de los espíritus, $\mathrm{Pa}$ trizi explica las posibles causas de su corrupción, y son 
precisamente esas causas las que determinan desde el lugar en el que ha de situarse la ciudad o su extensión hasta la existencia misma de las leyes y de los jueces. La dispersión de los espíritus suele deberse a dos cosas:

o porque todos, puros y naturales, salen del cuerpo, o porque dentro del cuerpo se corrompen. Se corrompen dentro del cuerpo por el exceso de condensación o de rarefacción, o por una cualidad venenosa, contraria a su sustancia propia. El exceso de densidad suele deberse al frío, tanto interior como exterior. La rarefacción proviene fundamentalmente del calor, tanto intrínseco como extrínseco. Y la cualidad venenosa también puede ser interior o exterior (Città felice, p. 7v).

Siguiendo la medicina galénica, según la cual la salud es el equilibrio de los cuatro humores - sangre, flema, bilis negra y bilis amarilla- y éstos dependen a su vez de las cuatro cualidades aristotélicas - lo frío, lo caliente, lo seco y lo húmedo- Patrizi concluye que en ningún cuerpo sano el exceso de frío o calor pueden proceder del interior del cuerpo. Los excesos de estas cualidades proceden del exterior, provocando el desequilibrio de los humores y la corrupción de los espíritus. Para evitar estos males, que ponen en riesgo la unión de alma y cuerpo, es necesario ubicar la ciudad en un lugar donde frío y calor estén equilibrados. La argumentación naturalista de Patrizi llega aquí al extremo de negar que quienes habitan en lugares demasiado cálidos, como Etiopía, puedan aspirar a la felicidad, pues corrompiéndose fácilmente sus espíritus, la vida no puede perdurar, y no perdurando la vida, no se puede practicar la virtud a lo largo de su entero camino (Città felice, p. 7v). Evitar el exceso de condensación se conseguirá evitando el frío, y para ello serán necesarios los trabajadores manuales de la comunidad, que habrán de construir edificios, ropas o calzados ${ }^{25}$. Mas también será preferible edificar la ciudad en lugares al reparo de los vientos fríos (cfr. Città felice, p. 8r. $)^{26}$. En cuanto a la venenosidad del aire, Patrizi no duda a la hora de definirla como el resultado de la corrupción o putrefacción del aire, que es el causante de las pestes y epidemias y que suelen producirse en lugares húmedos, paludosos, con aguas estancadas, poco ventilados y con árboles de hoja perenne. Patrizi no estaba haciendo más que seguir los cánones de la medicina hipocrático-galénica en cuanto a las causas de la enfermedad, que podían ser internas o externas. Estas últimas, a su vez, podían deberse a cuatro tipos de causas: una alimentación deficiente, las acciones del medio - tales como las heridas o traumatismos-, el clima y, por último, los venenos o miasmas. En este punto de La città felice, la política aristotélica se unía claramente al hipocrático texto Sobre los aires, aguas y lugares, donde se insistía en la necesidad de elegir el lugar de la ciudad atendiendo a los efectos que el clima puede tener sobre la salud ${ }^{27}$.
Con los principios de la medicina hipocrático-galénica, Patrizi legitimaba así la elección que Aristóteles, en la Política, hacía del emplazamiento que ha de ocupar la ciudad ideal: un lugar alto y escarpado para preservar la salud (Política, VII 11, 1330a1331b). No sólo el exceso de calor o frío y los aires venenosos eran causa de enfermedad, y de hecho todos los tratados de medicina galénica dedicaban especial atención a todas aquellas enfermedades que nacen de una vida desordenada, de una alimentación desequilibrada o de heridas mal curadas. Para evitar estos males que también acaban con los espíritus era necesario, escribía Patrizi, que existiesen en la ciudad "otro tipo de artesanos, que a estos males se opongan, y con cuya ayuda de su violencia nos liberemos. Tales son los médicos físicos, los cirujanos y sus ayudantes barberos, los stuffaiuoli (quienes trabajan en las saunas) y los boticarios ${ }^{28}$.

Bien es cierto, proseguía Patrizi, que no solo de enfermedad muere el hombre, pues también es posible que los espíritus vitales abandonen el cuerpo por una acción violenta, por un asesinato, en fin. Y contra esto ni el médico ni la medicina pueden hacer nada. En este caso la conservación de la vida queda en manos del ejército y de los gobernantes de la ciudad ${ }^{29}$. El gobernante, el legislador, ha de ocuparse de la salud de su ciudad como el médico ha de ocuparse de la salud del cuerpo del individuo. La ciudad es un gran cuerpo y el legislador, en cierto sentido, un médico de la ciudad, pues su fin último es mantener el orden para que la vida perdure y gracias a ella se pueda aspirar a la felicidad. El magistrado ha de establecer las normas y leyes que mantengan en perfecto estado la máquina generadora de espíritus y que eviten su «corrupción» violenta. Se habrá de preocupar del alma, pero antes que ello tendrá que dedicar sus esfuerzos legisladores a los bienes del cuerpo. A partir de esta premisa, Patrizi retoma su discurso fisiológico para explicar la tarea y misión de gobernantes y magistrados, empezando por la procreación:

el cuerpo tiene su origen en la generación. Y del cuidado de ésta deberá partir [el autor de las leyes]. Y dado que los hijos que vienen a la luz, salen de padre y madre, el legislador se deberá ocupar en primer lugar de éstos, pues concurriendo en la generación del hijo, según los médicos, el semen del padre y el semen y la sangre de la madre, para la rosbustez y fortaleza del generado, es necesario que el semen de ambos sea caliente. Siendo como es, que según sea la causa, así será el efecto que de ella derive. Sano será el semen que provenga de cuerpo sano, igual que será robusto si viene de robusto; y es robusto cuando en su estado natural es caliente, lo cual sucede cuando el hombre se encuentra en el estado y flor de su edad, lo cual en el hombre sucede entre los treinta y cinco y los cuarenta y nueve años y en la mujer entre los dieciocho 
y los cuarenta. Y aunque las mujeres puedan generar desde los catorce hasta los cincuenta, no obstante antes de los dieciocho el semen y la sangre, a causa de la temprana edad, es muy débil y húmedo, y tras los cuarenta se enfría (Città felice, pp. 16r-v).

De modo que el legislador tendrá que estar bien atento a la edad en que sus ciudadanos se den al acto de generar. Y no sólo, porque también deberá legislar sobre la época del año en la que los amantes se dan al sexo procreador, pues el frío del invierno debilitaría el calor del semen, y por tanto su calidad. Y hasta de la hora, pues después de las comidas el calor del cuerpo está empeñado en la digestión. De nuevo Patrizi se esforzaba en completar con argumentos fisiológicos lo ya mantenido por Aristóteles, pues sus palabras eran prácticamente una paráfrasis de lo afirmado por éste cuando en la Política decía que el legislador, en pos de la felicidad de la ciudad, ha de velar por la salud del cuerpo (cfr. Aristóteles, Política VII 16, 1334a-1336a). Lo que sigue, desde la atención que se ha de prestar al bienestar de las mujeres embarazadas para que alumbren ciudadanos sanos, al cuidado de los niños y su posterior educación, no era más, en efecto, que un breve resumen del Libro VII de la Política aristotélica. Se insistía, como hacía el Estagirita, en la necesaria enseñanza de la gramática, la música y la pintura (cfr. Città felice, pp. 18r-19r), las cuales el legislador se había de ocupar de que fuesen infundidas en el pecho de los jóvenes. La música podía imprimir una cierta cualidad en el carácter, ayudaba a motivar al intelecto y pacificar el alma siempre según los diferentes ritmos (cfr. Aristóteles, Política VIII 3-7, 1337b-1342b), mientras que la pintura abría la puerta a la especulación (cfr. Aristóteles, Política VIII 3, 1338b) ${ }^{30}$. Nada había en esta referencia a la música que evocase la platónica armonía del mundo, nada que hiciese sospechar algún vínculo con la interpretación médica, mágica y terapéutica de la música expuesta por Marsilio Ficino ${ }^{31}$. Patrizi aprovechaba este comentario sobre la educación de los jóvenes para afirmar que todo el conocimiento procede de los sentidos, y que solo a partir de ellos se abre el camino al entendimiento, recordando aquella máxima aristotélica según la cual «nihil est in intellectu quod non prius fuerit in sensu». Pero aquí sí, el privilegio concedido a la vista y el oído, "los más nobles de todos los sentidos", y a partir de los cuales nace el deseo de conocer las causas y el causante de tanta armonía y belleza, evocaba sin lugar a dudas las palabras de Marsilio Ficino ${ }^{32}$. En cuanto a la gramática, parece clara la influencia que debieron ejercer en Patrizi los comentarios de su profesor en Padua, RoborteIlo, que además de insistir en la importancia de la educación de los jóvenes para construir un estado perfecto, se concentraba en la importancia de la retórica, la oratoria y la gramática ${ }^{33}$.
El cuerpo de la ciudad ideal, mantenido en vida gracias a los espíritus, estaba jerárquicamente organizado. Este cuerpo aristocrático tenía rígidamente ubicadas sus potencias y funciones. En su parte más baja y vil, pero no por ello menos necesaria y vital, se encontraban los trabajadores manuales, de naturaleza esclava e incapaces de gobernarse por sí mismos. En la parte más alta de la pirámide, como en el cuerpo están el corazón y el cerebro, se situaban las milicias, y por encima de ellas los magistrados, y más arriba aún, en la cúspide, los sacerdotes. Estos dos últimos estamentos eran los auténticos depositarios de la sabiduría, dedicados fundamentalmente a practicar la potencia «más sublime» del alma, la contemplación, y por tanto a ejercer las virtudes especulativas (Città felice, pp. 15v-16r). A Aristóteles no le tembló el pulso a la hora de negar a los trabajadores manuales la posibilidad de aspirar a la felicidad, dado que la felicidad era la práctica de la virtud, y ésta sólo se podía alcanzar gracias al ocio y la contemplación, no llevando una «vida innoble y contraria a la virtud» como la de los agricultores y el resto de los trabajadores manuales (Aristóteles, Política VII 9, 1328b-1329a). La ciudadanía y la felicidad eran derechos exclusivos de quienes no debían trabajar con sus propias manos. Patrizi compartía sin ambigüedades esta cruel división: "Y diré, en fin, que nuestra ciudad tiene dos partes, una servil y miserable, la otra señora y beata, y esta es la que propiamente ha de ser llamada ciudadana ${ }^{34}$.

\section{UNA MEDICINA PLATÓNICA PARA UNA POLÍTICA ARISTOTÉLICA}

Desvelada la clave aristotélica con la que Patrizi diseñó La ciudad feliz, queda preguntarse hasta qué punto era el fruto de un convencido platónico. Resta responder a por qué Patrizi, tras ofrecer su obra al lector como unas "alas de Dédalo» para elevarse en vuelo tras el divino Platón, se lanzaba a una apología de la Política aristotélica. Lo más fácil sería pensar que se trataba de una excepción a su platonismo, que en lo referente a la ética y la política, Patrizi se inclinaba más por la propuesta del Estagirita. Y en buena medida es cierto, pues el Chersino apostaba decididamente, como muchos de sus coetáneos, por una estructura jerárquica y aristocrática del estado para la que la política aristotélica era un excelente modelo. Pero $L a$ ciudad feliz no era una mera excepción, un paréntesis, una brecha aristotélica en una mente platónica. El objetivo de Patrizi era caminar por la senda de Platón sin renunciar a la política aristotélica. O mejor dicho, demostrar que la estructura oligárquica del estado propuesta por Aristóteles descansaba sobre una metafísica y una filosofía natural platónicas ${ }^{35}$.

La estrategia conciliadora puesta en marcha por Patrizi consistió en retomar el antiguo vínculo entre filosofía y medicina, pero dejando ahora de lado la filosofía 
natural aristotélica que había servido de base a la medicina galénica en las universidades medievales para apostar, en cambio, por una conciliación entre medicina y filosofía platónica. Organización política, ética y medicina retomaban en La ciudad feliz un antiguo vínculo, una relación que ya había empezado en tiempos de los griegos. Si la organización social y los principios éticos fueron un modelo para la medicina o en cambio esta última inspiró las teorías ético políticas, es una cuestión sobre la que mucho se ha discutido. Sobre lo que no parece haber muchas dudas es que los filósofos presocráticos solo pudieron empezar a desarrollar su concepto de physis como un todo ordenado, equilibrado y regular, gracias a su privilegiada situación de testigos de un orden social y político. Los médicos hipocráticos, a su vez, tomaron de los "fisiólogos» jonios y sicilianos su concepto de naturaleza, aspirando a basar en él la técnica médica entendida como un hacer sabiendo lo que se hace, como una intervención en la naturaleza fundada en el conocimiento de la naturaleza. Como si de un círculo se tratase, Platón y Aristóteles volvieron sus ojos a las enseñanzas médicas de los hipocráticos para comprender las raíces de la política. Difícilmente habrían podido evitarlo, siendo como era una medicina que había hecho de los conceptos de «naturaleza justa» (dikaíe physis) o de virtud (aretè) los pilares de su explicación de la salud y la enfermedad ${ }^{36}$. Para los hipocráticos la salud era el buen orden de la naturaleza, tanto de la de cada cuerpo individual como de la polis. Un cuerpo sano era aquel cuyo estado vital era justo (dikaios), así como la enfermedad, siendo un desequilibrio, suponía una ruptura de la justicia. Y así pareció tenerlo bien presente Platón cuando en el Gorgias Sócrates, criticando la retórica de los sofistas, establecía el paralelismo entre la salud del cuerpo, de la que se ocupa la medicina, y la salud del estado, preocupación principal de los legisladores (Gorgias, 464a-465a); o en el Fedro, cuando explícitamente se refería a Hipócrates para afirmar que los cuidados del alma y de la virtud han de seguir el mismo método que el empleado por los médicos (Fedro, 270b270c). Son solo algunos ejemplos.

El siglo XVI fue una época de renacimiento de aquel antiguo vínculo entre filosofía y medicina. La escolástica había insistido en la indisolubilidad ente la filosofía natural aristotélica y la medicina galénica. Ahora le tocaba el turno al olvidado platonismo. En 1516 Symphorien Champier publicaba en París su Symphonia Platonis cum Aristotele, et Galeni cum Hyppocrate, en un intento de demostrar la armonía entre los cuatro grandes. Más allá de ciertas tensiones, los humanistas del siglo XV, profundamente preocupados por los problemas de la vida civil, siempre atentos a la especulación ética y los problemas del estado, fueron también los grandes estudiosos de la medicina antigua. Angelo Poliziano, Giovanni Pico della Mirandola o Nicolò Leoniceno acumulaban en sus bibliotecas los textos de los médicos de la Antigüedad, los traducían con esmero y les hacían compartir espacio con las obras de Platón ${ }^{37}$. El gran escollo que durante siglos había presentado la medicina galénica era el problema de la inmortalidad del alma, que el médico de Pérgamo había considerado resultado de las funciones del cuerpo, y por tanto mortal. Tal conclusión coincidía, aunque por motivos diferentes, con la de Aristóteles, que definía el alma como forma del cuerpo. Pero no olvidemos que en las universidades medievales la medicina galénica se estudiaba sobe todo en la versión dada por Avicena en su Canon, donde realizando una síntesis entre Galeno y Platón había defendido tenazmente la inmortalidad del alma. En un ambiente intelectual tan preocupado por esta cuestión como fue la Italia de los siglos XV y $\mathrm{XVI}$, el dualismo alma-cuerpo de Platón parecía ofrecer una senda prometedora. Una senda que, por otra parte y quizá sin demasiado éxito, ya había intentado transitar el mismísimo Galeno cuando escribió el De Placitis Hippocratis et Platonis ${ }^{38}$.

De toda aquella corriente humanista de médicos de la virtud, la felicidad y la justicia, uno de ellos consiguió convertirse en la figura emblemática de la nueva medicina del alma: Marsilio Ficino. Entre sus páginas encontramos la respuesta a por qué Patrizi escribió aquella Ciudad feliz en la que, tras prometer al lector una alas de Dédalo para seguir la senda de Platón, se dedicaba a parafrasear a Aristóteles. Se podría incluso decir que su ciudad era la de Aristóteles explicada con la medicina de los espíritus de Marsilio Ficino, quien ya un siglo antes, en su De vita coelitus comparanda, había intentado demostrar cómo para poder alcanzar el conocimiento del bien y de la virtud había que prestar un especial cuidado a los espíritus del cuerpo ${ }^{39}$. El objetivo del De vita era conservar la salud del sabio. Ficino quería, por encima de todo, ser un médico del alma, pero en esta vida para cuidar el alma había que cuidar el cuerpo. Ya llegaría el momento en el que el alma se separase del cuerpo y se pudiese librar de sus necesarios cuidados, pero la vida, como también recordaría Patrizi en su Ciudad feliz, es ese periodo transitorio en el que el alma está unida al cuerpo. En este último se encuentran, encerrados y en continuo movimiento, los espíritus, que Ficino considera los primeros instrumentos del alma incorpórea y eterna. Los filósofos, buscadores del bien y la verdad, escribía Ficino, se habían olvidado de los espíritus, que en realidad eran la herramienta con la que poder abarcar todo el universo (De vita, Libro I, cap.1, en Opera omnia, T. I, pp. 495-496). Está claro que los espíritus de que hablaba Ficino entroncaban con la tradición médica hipocrático-galénica, pero no se limitaban a ella, teñidos como estaban de valores metafísicos, teológicos y cosmológicos ${ }^{40}$. Ellos son los que vinculan el mundo de lo inteligible con el material y corpóreo mundo terreno, al hombre con el gran animal que es el mundo y que como el primero también posee un spiritus (De vita, Libro III, caps. 3-4, en Opera omnia, T. 
I, pp. 534-536), y gracias a ese vínculo el hombre puede recuperar el a veces olvidado origen de su alma, que no es otro que el mundo de las Formas.

Francesco Patrizi retomó, a distancia de un siglo, la filosofía médica de los espíritus de Marsilio Ficino para dar una explicación de la salud del cuerpo del estado $^{41}$. Daba así una respuesta a ese indefinido y poco claro origen natural de la ciudad del que habían hablado Aristóteles y Platón. Pero la clave de lectura platónica y ficiniana de La ciudad feliz, dejando aparte guiños y promesas iniciales al lector, no se encuentra en sus páginas, sino en las de uno de los textos que le siguen en el volumen de 1553, el Della diversità dei furori poetici ${ }^{42}$. Iniciaba este diálogo planteando la cuestión de por qué unos poetas eran más dados a una materia que a otra. Algunos brillaban en el verso heroico, otros en el elegíaco, en el sáfico o el yambo. En este caso la cuestión, decía Patrizi, «superaba toda la peripatética filosofía»: la respuesta se encontraba en Platón. Ahora verdaderamente comenzaba el ascenso a las altas cimas que Patrizi había prometido en la dedicatoria de La ciudad feliz. A su nuevo interlocutor, el señor Mariano Savello, ofrecía de nuevo las alas de Platón:

Y V. S. entenderá mejor esta explicación si, cogidas las alas de Platón, con ellas volamos hasta el Cielo, para poder allí, más de cerca y casi presencialmente, contemplar la razón de tan elevada dificultad. Tome así pues V. S. estas alas y juntos emprendamos el vuelo desde aquel memorable y eminente lugar de Horacio: «Demócrito creyó que más vale el talento que el vil arte y desterró del monte de las Musas a los poetas cuerdos» (Diversità, p. 45 r). ${ }^{43}$

La cita de los versos de Horacio ponía sobre la mesa la intención de Patrizi: escapar de una concepción de la poesía entendida como pura técnica, del retrato del poeta como artifex, para abrazar la teoría platónica del furor. No se podía ser buen poeta sin un halo de locura, "adflatu quasi furoris», como había escrito Cicerón, y con razón Horacio había excluido de Helicón, el escarpado monte consagrado a Apolo y las Musas, a los poetas sensatos. Pero el poeta no era simplemente un loco, ni siquiera era un loco. El furor muy a menudo es confundido con la locura, cuando en realidad es la auténtica sabiduría. Patrizi retomaba así la teoría del furor poético expuesta por Ficino en su «De divino furore» ${ }^{44}$. El verdadero y buen poeta es aquel que une en su ejercicio de la poesía el furor y el ingenio. Este último es la buena disposición para el aprendizaje, la capacidad de la inteligencia, rápida o lenta, despierta o adormecida (Diversità dei furori poetici, p. 45v). El furor, por su parte, y «según nos enseña Platón en el Fedro», puede ser natural o divino. Y si el natural depende de los humores del cuerpo, el divino, que puede ser a su vez poético, mistérico, profético o amoroso, desciende del cielo. Entender cómo llega al poeta este furor pasa por aceptar que «todo este universo corpóreo está animado y gobernado por un alma racional y eterna y que los elementos inferiores también son movidos y agitados por similares almas» (Diversità dei furori poetici, 46r). El gran problema era cómo explicar la unión de las almas, creadas por Dios en el mundo de lo inteligible, eternas e incorpóreas, con el cuerpo material de los seres naturales, astros y hombres incluidos. Para ello Patrizi recurría a una antigua idea de los neoplatónicos y recientemente recuperada por Ficino: el "corpicello sottilissimo", (cfr. Commentarium in Convivium Platonis, Orat.VI, cap. 4, en Opera omnia, cit., T. II, pp. 1342-1345), hecho de la misma substancia que los cielos y del cual se revisten las almas en el momento de su nacimiento. Es el vehículo del alma, ese carro del que hablaba Platón en el Fedro y que en su travesía desde el mundo de lo inteligible hasta el mundo terreno se va impregnando de las virtudes de los astros, aprendiendo, por así decir, de las almas de los planetas, a las que los antiguos llamaron Musas $^{45}$. El corpicello eterero une lo inteligible con lo sensible e infunde en el hombre, aún sin éste ser consciente de ello, el conocimiento de las formas supremas. En el momento del nacimiento, y durante la infancia, el hombre no recuerda los orígenes de su alma, pero después empieza a rememorar el mundo de las Ideas del cual procede. El vínculo del alma con las musas es un vínculo de simpatía, una cadena que las liga para siempre, y dado que lo afín se atrae, las musas atraen a sí al alma despertando el furor (Diversità dei furori poetici, pp. 49r-v). La inclinación del poeta a tratar una u otra materia está, pues, determinada astrológicamente y esconde la auténtica sabiduría.

El furor es el despertar del recuerdo del mundo de las Ideas, del mundo de la perfección y de la plenitud, del paraíso originario de felicidad de las almas. Un furor que ha de ser estimulado y despertado por el estudio. El auténtico conocimiento es una suma de arte y furor poético. Patrizi había comenzado su Ciudad feliz describiendo ese estado de desazón de los hombres al recordar vagamente, en vida, una felicidad propia de ese paraíso de la abundancia y la perfección del que derivan todas las cosas. Ofrecía su obra como una vía, un primer paso, para recuperarla. Cobraba así sentido que describiese una aparente paráfrasis de Aristóteles como unas «alas de Dédalo» con las cuales volar siguiendo a Platón. La explicación de la ciudad como una estructura al servicio de la conservación de los espíritus permitía entender la política como una medicina del estado, pero una medicina, en último término, al servicio del alma, como había pretendido Ficino en su De vita. La política, y así lo recordará el propio Patrizi unos años más tarde en sus Diálogos sobre la Historia (1560), tenía también como fin último perseguir el estado de bienestar y felicidad. Quedaba así tejido el vínculo entre medicina y política, entre el estado aristocrático de la política aristotélica y la platónica medicina de los espíritus y del alma. 


\section{NOTAS}

1 Son numerosos los estudios especializados y eruditos sobre los diferentes aspectos de la obra de Patrizi, pero se echa aún de menos una biografía intelectual de conjunto. Véase en tanto Arcari (1935), Bolzoni (1980), así como los textos recogidos en Castelli (2002) y Vasoli (1989). Las noticias sobre la biografía de Patrizi son fragmentarias y no siempre claras y se basan, en buena medida, en la carta autobiográfica que en 1587 envió a Baccio Valori y ahora publicada en Francesco Patrizi da Cherso, Lettere ed opuscoli inediti, ed. de Danilo Aguzzi Barbagli, Florencia, Istituto Palazzo Strozzi, 1975, pp. 45-51.

2 Este primer volumen de las Discussionum peripateticarum Libri XIII fue publicado en Venecia por el editor Dominicum de Franciscis. Una década más tarde Patrizi, en 1581, daría a la luz la continuación de esta obra, en este caso con el título Discussionum peripateticarum tomi IV quibus Aristotelicae philosophiae universa historia atque dogmata nunc veterum placitis collata, eleganter et erudite declarantur, publicado en Basilea por Pernam Lecythum. Sobre la crítica de Patrizi a la filosofía aristotélica en las Discussionum, véase Vasoli (1981) y (1996); Mucillo (1975) y (1981); Antonaci, 1984; Leinkauf (1990). El interés de Patrizi por la historia, tanto en lo que se refiere a la concepción del tiempo y el desarrollo del saber como al modo de narrarlo, había quedado ya de manifiesto en una de sus primeras obras, los diálogos Della Historia, publicados en Venecia en 1560 y volvería explícitamente sobre las mismas cuestiones en dos obras escritas estando ya en Ferrara: Methodus historica, duodecim eiusdem argumenti scriptorum, tam veterum quam recentiorum, commentariis adaucta, Basilea: Petri Pernae, 1576 y el Artis historicae penus. Octodecim scriptorum tam veterum quam recentiorum monumentis...instructa, Basilea: Petri Pernae, 1579. Sobre la concepción de la historia en Patrizi véase la interesante interpretación de Plastina (1992).

3 Sobre las censuras impuestas a la obra y el proceso de revisión de la Nova de universis philosophia véase Ricci (2008), pp. 291363 y Puliafito (1987), donde se pueden encontrar además ulteriores informaciones bibliográficas sobre esta cuestión.

4 En realidad Pia Castelli, que es una de las mejores estudiosas de la obra de Patrizi, se refiere en este caso solo a La ciudad feliz, aunque considero que haría extensivas sus propias palabras al resto de los textos que componen el volumen patriziano publicado en 1553. Cfr. Castelli (2002), p. 23.

5 I Mondi se publicó en Venecia en 2 volúmenes y en ellos Doni se mostraba tremendamente irónico y pesimista con la sociedad y los intelectuales de su tiempo. Sobre su utopía, véase Grendler (1965) y (1969); Curcio (1941).

6 Entre quienes han negado tajantemente la pertenencia de La città felice al género utópico se encuentra Luigi Firpo; véase Firpo (1964), p. 564; Id., (1948), pp. 84-85 e Id., (1975), pp. 7-46. Otras dos estudiosas del pensamiento de Patrizi, Lina Bolzoni y Paola M. Arcari, han afirmado que el referente de La città felice es la propia ciudad de Venecia; véase Bolzoni (1980), pp. 38-46 y Arcari (1935), cap. 2. Por su parte, C. Vasoli considera que intentar clasificar el texto de Patrizi en el género utópico o interpretarlo como un reflejo de la sociedad veneciana no es el fondo de la cuestión, aunque admite la influencia de la Venecia real; véase Vasoli (1989), pp. 11-15. Castelli niega tanto que se trate de una utopía como de una imagen literaria de Venecia, cfr. Castelli (2002), p. 21-27. Véase también Tafuri (1985), pp. 161 y ss., Moreno Chumillas (1991); Comparato (2006), pp. 73-74.

7 Véase Hankins (1996).

8 Sobre este tema, véase Besso et al. (2007).

9 Véase Lines (2002).

10 La influencia de Robortello se hará todavía más patente en posteriores obras de Patrizi, en especial en los diálogos DeIla Historia, que se publicarán en 1560. Sobre esta cuestión, véase Vasoli (1989), pp. 33 y ss.

11 El tema de la concordia universal de todas las formas de sabiduría cobró una gran relevancia -con implicaciones teológicas y políticas- en la Europa de los siglos XV y XVI. Estaba ya presente en Marsilio Ficino y en Giovanni Pico della Mirandola, quien en su Oratio de hominis dignitate se presentaba a sí mismo como apóstol de la pax philosophica. Más cercano aún al momento y lugar que nos ocupa, Francesco Giorgio Veneto (Zorzi) insistía en que las "disonancias" de las voces filosóficas eran solo apariencias bajo las cuales subyacían las verdaderas armonía y concordia (cfr. su De Harmonia Mundi, Venecia, Bernardino Vitali, 1525, pp. 26v-27r; existe una excelente edición de esta obra, con texto latino y traducción italiana, de S. Campanini, con título L'armonia del mondo, Milán, Bompiani, 2010, en esta edición las páginas citadas corresponden a 165-171). La reflexión sobre la concordia universal tuvo un fuerte vínculo con el renacimiento de la filosofía hermética, lo cual se hizo especialmente patente en la edición de los textos herméticos que Patrizi publicó junto con su Nova de Universis Philosophia en 1591, muy en particular en las páginas de Mystica Aegyptorum et Caldaeorum, à Platone voce tradita , pp. 1, 4, 41, 49, 53-54.

12 Cfr. Lines (2007), pp. 308-309.

13 Este proyecto fue acogido por el círculo de Federico Badoer y su Accademia della Fama, fundada en 1557 y de la que Patrizi empezó a formar parte ese mismo año. Sobre esta cuestión, véase Tafuri (1985), pp. 161 y ss.

14 Sobre la identidad de estos destinatarios, compañeros de Patrizi en sus años de estudiante en Padua, y los intereses que pudo tener Patrizi para dedicarles a ellos La ciudad feliz, véase Castelli (2002), pp. 29-30.

15 "Beatitudo" y "felicitas" eran los dos términos latinos empleados para traducir el griego "eudaimonia", y aunque Patrizi los usa aparentemente como sinónimos, hay que recordar que mientras "felicitas" se refería solo a la felicidad terrena, "beatitudo" se empleaba para significar el estado perfecto de felicidad que se alcanza en el paraíso tras la muerte del cuerpo. En este sentido, véase el texto de Marsilio Ficino, "Quid sit felicitas", en Opera omnia, Basilea, 1576, T. I, pp. 662-665. 
16 La idea de la existencia de tales aguas supracelestes deriva de Génesis 1, 6-7. Giovanni Pico della Mirandola en su Heptalus (Florencia, 1490), Francesco Giorgio Veneto (Zorzi) en el De Harmonia Mundi (Venecia, 1525, pp. 128r-129v. / ed. de S. Campanini, cit., pp. 742-749) o Giulio Camillo Delminio en su Idea del Theatro (Florencia, 1550, pp. 22-23), todos ellos bien conocidos por Patrizi, hicieron una lectura neoplatónica del tema de las aguas supracelestes, identificándolas con el Verbum Dei, y este a su vez con el mundo platónico de la formas. Las ideas, eternas e inmutables, situadas más allá de los cielos corpóreos, fluyen hacia el mundo inferior como fluyen las altísimas aguas, atravesando en su camino las esferas de los astros, gracias a cuya influencia se imprimen en las cosas materiales. Sobre este tema en la Città felice de Patrizi, véase Vasoli (1989), pp. 5-6 y Piaia (1996). Patrizi volverá a aludir a estas aguas supracelestes de las que todo mana en el Discorso sulla diversità dei furori poetici, p. 49 r-v.

17 Cesare Vasoli ha señalado la marca platónica, cabalista y ficiniana de este pasaje sobre las aguas supracelestes, subrayando su similitud con algunas líneas del Heptalus de Pico della Mirandola y del De Harmonia Mundi de Francesco Zorzi; cfr. Vasoli (1989), p. 6.

18 La concepción aristotélica de la felicidad se encuentra fundamentalmente en los libros I y X de la Ética a Nicómaco. Sobre la crítica a Platón en este aspecto, véase I, 1096a 10-1097a 15.

19 Al hablar del séptimo grado, Patrizi se está refiriendo a la clasificación de los bienes y virtudes que Aristóteles hacía en Ética a Nicómaco, I 1098b 10 - 1099b 5; cfr. Città felice, pp. 5r-v.

20 Sobre el naturalismo político de Aristóteles, véase Keyt (1991), donde se subraya la aparente contradicción entre la defensa del carácter natural de la ciudad y su constitución y organización por parte de los magistrados. Miller (2000) mantiene que "natural" en la Política tiene un significado completamente diferente al empleado en la Física. Véase también Reeve (2009), pp. 512-25.

21 En la polisemia, usos y transformaciones del concepto de spiritus residen, en mi opinión, importantes claves para entender las mutaciones acaecidas en la filosofía natural de los siglos XVI y XVII. Dada la amplitud del tema, no es posible abordarlo con mayor detenimiento en este artículo, pero remito a Verbeke (1945), Fattori - Bianchi (1984), Boyd (1965), Hirai (2011).

22 Aristóteles había aludido a la analogía entre cuerpo y ciudad en Política III 4, 1277a 6-7: "La ciudad está compuesta de elementos distintos, como el ser vivo, por de pronto, de alma y cuerpo; y el alma de razón y apetito". Utilizaba esta analogía para sostener que "la virtud de todos los ciudadanos no es única, no es la misma virtud", pero no la desarrollaba más hasta el punto que lo hace Patrizi.

23 Según Aristóteles, "hay varias clases de esclavos, ya que sus actividades son varias. Una parte de ellos la constituyen los trabajadores manuales. Estos son, como lo indica su nombre, los que viven del trabajo de sus manos, entre los cuales está el obrero artesano. Por eso, en algunas ciudades antiguamente los artesanos no participaban de las magistraturas, hasta que llegó la democracia en su forma extrema. Así pues, ni el hombre de bien, ni el político, ni el buen ciudada- no, deben aprender los trabajos de tales subordinados, a no ser ocasionalmente para su servicio enteramente personal. De lo contrario, dejaría de ser el uno amo y el otro esclavo", Política, III 4, 1277a. Y más adelante (III 4, 1277b 5- 1278a 2-6) proseguía: "Realmente, ¿̇es ciudadano solo el que puede participar del poder o también hay que considerar ciudadanos a los trabajadores manuales? [ ] La verdad es que no hay que considerar ciudadanos a todos aquellos sin los cuales no podría existir la ciudad [ ] En los tiempos antiguos y en algunos lugares, los trabajadores manuales eran esclavos o extranjeros, y por eso aún hoy lo son la mayoría. La ciudad más perfecta no hará ciudadano al trabajador". Véase también Política VII 9, 1329a, 7-10; VII 10, 1330a, 13-14.

24 Al empezar a tratar el tema de la conservación de los espíritus de la ciudad, Patrizi parece dar un salto y deja de referirse exclusivamente a los espíritus naturales, de cuya generación están encargados los trabajadores manuales, para hablar en términos generales de los tres tipos de espíritus.

25 Aquí Patrizi incurre en una cierta contradicción, pues mientras había reservado para campesinos, agricultores y artesanos la tarea de generar los espíritus naturales, ahora atribuye también a estos últimos la tarea de conservarlos.

26 Patrizi mencionaba como ejemplos de tales ciudades bien ubicadas la Verona de su época y la Atenas de la Antigüedad, lo cual bien podría ser entendido como un indicativo de su propósito de presentar su descripción de la ciudad feliz como un espejo de la República de Venecia.

27 El hipocrático Sobre los aires, aguas y lugares insistía en la relación entre los hábitos sociales, las virtudes y el medio geográfico y climático. Se trataba de uno de los textos más importantes del Corpus Hipocrático; su primera traducción del griego se publicó en París en 1512 y de él se hicieron al menos diez ediciones comentadas en el s. XVI.

28 Nótese que Patrizi solo considera artesanos a los "médicos físicos", pues un lugar muy diferente correspondería a los "médicos filósofos", conocedores de los principios de la naturaleza y de las causas de la salud y la enfermedad. Sobre esta distinción, véase Maier-Kapoor (2010), pp. 33 y ss.

29 Patrizi aprovecha aquí para hacer una primera referencia al amor como forma de conocimiento. Solo el amor y la ausencia de enemistades entre los ciudadanos, afirma, pueden evitar que se maten entre ellos, pero dado que el amor solo se pude sentir por aquello que se conoce, será necesario que los ciudadanos se conozcan entre sí. Es tarea de los gobernantes dirigir y orquestar estos vínculos de conocimiento y cooperación, estableciendo clases, coordinando dinastías, organizando eventos públicos o impidiendo que la ciudad crezca desmesuradamente; cfr. Città felice, pp. 9v-10r. Se retoma aquí el tópico de las dimensiones que ha de tener la ciudad, abordado por Aristóteles en Política VII 4, 1326a$1326 \mathrm{~b}$, donde se mantiene que la ciudad ideal debe ser de tamaño reducido.

30 Compárese con lo afirmado por Platón en República VII 525c; 526d; 529a.

31 Sobre este tema véase Walker (2000), pp. 3-29. Lejos de mi intención negar que Patrizi estuviese de acuerdo con la 
concepción ficiniana de la música como medicina del alma y el cuerpo, simplemente considero que leer las palabras que Patrizi dedica a la música en La città felice en esta clave es una extensión no adecuada de su filiación platónica. Sobre el valor de la música en la filosofía de Patrizi, véase Prins (2009).

32 Cfr. Ficino, Commentarium in Convivium Platonis De amore, Orat. V, cap. II, en Opera Omnia, T.II, pp. 1334-35 (trad. esp. de Rocío de la Villa, Madrid, Tecnos, 2008, pp. 87-89).

33 Sobre este aspecto, véase Castelli (2000), pp. 16-17.

34 Sorprende quizá el escasísimo espacio que Patrizi dedica a la caracterización de los sacerdotes de la ciudad y a la función que ha de cumplir la religión. Muy probablemente se estaba guardando un as en la manga, una carta que empezará a jugar en los textos que siguen a La ciudad feliz en el volumen de 1553, en especial el dedicado al furor. Cesare Vasoli, que con tanto cuidado y erudición estudió todos los escritos de Patrizi, interpretó la función que éste atribuye al sacerdote como la evocación del sabio rey del mundo, del máximo gobernante filósofo del que hablaba Platón en la República (L. IV, 473a), de los sacerdotes depositarios de la sabiduría suprema de los tiempos de los egipcios, de aquel Hermes Trismegisto que tanto había seducido a Ficino. A Vasoli no le faltaban razones y buenos argumentos para realizar esta interpretación, pero lo cierto es que en las páginas de La ciudad feliz, el auténtico sabio es el gobernante, el legislador, no el sacerdote. El gobierno de la ciudad, dice Patrizi, ha de estar en manos de los más sabios, prudentes y ancianos si quiere aspirar a la felicidad. Nada se afirma acerca de los especiales dones divinos del sacerdote, ni de su determinación astrológica. Lo cual, una vez más, no significa que Patrizi no compartiese estas ideas, sino que en La ciudad feliz no se estaba refiriendo a ellas, sino parafraseando a Aristóteles, según el cual al sacerdocio solo pueden llegar los auténticos ciudadanos, aquellos que tras dedicarse toda una vida a la guerra o a la vida contemplativa y al gobierno de la ciudad llegan a una edad avanzada (cfr. Città felice, p. 10v; Aristóteles, Política, VII 9, 1329 a).

35 Véase supra p. 10 y n. 13

36 Véase (Jaeger) 1957; Laín (1982), pp. 51-58, 101 y ss., 185 190. Tanto en los textos hipocráticos como en las obras de Galeno, aparece repetidamente la idea de que la educación del alma necesita de la medicina, y en este sentido la medicina forma parte de la ética y la moral. Un análisis actualizado de las interpretaciones sobre esta relación se puede leer en Molina González (2012).

37 Sobre las relaciones entre humanismo, filosofía y medicina véase Kristeller (1978); Maier-Kaapoor (2010), pp. 23-51, Siraisi (2007), Hirai (2011).

38 Existe una cuidadísima edición de Ph. De Lacy, Berlin, Akademie Verlag, 1978. Sobre el problema de la inmortalidad del alma en Galeno, véase el estudio introductorio de P. N. Singer a la edición inglesa de Galeno Sellected Works (Oxford, Oxford University Press, 1997, pp. 150 y ss.).

39 Marsilio Ficino terminó de escribir el De vita en 1489. Sobre este texto de Ficino, véase Bullard (1990), Copenhaver
(1984), Garin (1981), Allen and Rees (2002), Kristeller (1943); Walker (2000); Garfagnini (1986). Existe una traducción española del De vita realizada por Luigi Cornaro (Madrid, Asociación Española de Neuropsiquiatría, 2006). Sobre la denominada "medicina astrológica", véase Hirai (2014).

40 Cfr. Walker (2000), p. 12-13.

41 Véase Muccillo, M. (1986b).

42 La città felice debió ser escrita antes del 21 de julio de 1551, fecha de la dedicatoria a Della Rovere, mientras que el Della diversità dei furori poetici nació de una discusión en casa de Mariano Savello en enero de 1552. Creo que esta escasa diferencia de meses, y el hecho de que Patrizi eligiese aquellos temas para la publicación de su primera obra, es una prueba de que ya para entonces había madurado en él el proyecto de emprender una lectura de la política y la poética en clave platónica. Por su parte, la Lettura sopra il soneto del Petrarca tiene fecha de 7 de septiembre de 1551 y en ella aparecen también muchos de los temas de los otros dos textos, tales como la clara defensa de Platón, el gobierno que el mundo de los astros ejerce sobre el mundo terreno o la idea del "corpicello etereo".

43 En el original se lee: "La quale [explicación a la cuestión planteada] V. S. intenderà meglio se prese I'ale di Platone, con esso meco [sic] volerà infino in Cielo, per poter quivi, più di vicino, et quasi presentialmente contemplare, la cagione di questa così alta dificoltà. Pigli adunque V.S. quest'ale, et insieme prendiamo il volo, da quel luogo, rilevato et eminente di Horatio: ingenium misera quia fortunatius arte, credit, et excludit sanos Helicone poetas Democritus". En el Ars poetica (295-96) Horacio dice: “Por culpa de Demócrito, que cree / que más vale el talento que el vil arte / y destierra del monte de las Musas / a los poetas cuerdos, una buena / parte de ellos nunca se preocupa / de cortarse las uñas o la barba, / prefiere los lugares escondidos / y rehúye los baños. Pues por ello / logrará premio de poeta y fama / el que nunca someta su cabeza / [ ] a ningún peluquero" (según trad. de J. A. González Iglesias, Madrid, Cátedra, 2012). Los versos de Horacio se refieren a su reflexión sobre la dualidad arte/ingenio y a su crítica a quienes, como Demócrito, consideraban la poesía fruto exclusivo del furor y retrataban al poeta como a un loco poseído. Horacio mantenía que el ejercicio de la poesía ha de resultar de un equilibrio entre arte e ingenio, furor y virtud.

44 Cfr. Opera omnia, T. I, pp. 612-19. Véase la edición de este texto realizada por S. Gentile, que se encuentra en Ficino, Lettere, Florencia, Olschki, 1990, pp. 19-28, y sobre este escrito ficiniano véase Gentile (1983) y Allen (1984), pp. 41-67. Me remito también a Huss (2011), quien en p. 23, n. 8 aporta precisas indicaciones bibliográficas. Sobre la concepción del furor poético en Patrizi y su identificación entre poesía y auténtica sabiduría, véase Bolzoni (1980), pp. 26-38; BuffetMecarelli (2003).

45 Sobre este interesante concepto de "cuerpo etéreo", su historia, su uso por parte de Ficino y sus similitudes y diferencias con el concepto de "spiritus", véase Walker (1958) y (2000), pp. 39-40. Véase también Granada (1984), pp. 51-54. 


\section{BIBLIOGRAFÍA}

Allen, Michael J. B. (1984), The Platonism of Marsilio Ficino. Berkeley, University of California Press.

Allen, Michael J. B. y Rees, Valery (eds.) (2002), Marsilio Ficino: His Theology, His Philosophy, His Legacy, Leiden-Boston, Brill Academic Publishers.

Antonaci, A. (1984), Ricerche sul neoplatonismo del Rinascimento. Francesco Patrizi da Cherso. Vol. I: La redazione delle opere filosofiche. Analisi del primo tomo delle "Discussiones", Lecce, Salentina.

Arcari, Paola M. (1935), II pensiero politico di Francesco Patrizi da Cherso, Roma, Arti Grafiche Zamperini.

Besso, Giuliana; Guagliumi, Barbara y Pezzoli, Federica (2007), "Accademia e politica attiva: le edizioni, le traduzioni e i commenti alla Politica di Aristotele in Italia nei secoli xv-xvi", Res Publica Litterarum, Instituto de Estudios Clásicos "Lucio Anneo Séneca", Suplemento monográfico "Tradición clásica y universidad", pp. 3-22.

Bolzoni, Lina (1980), L'universo dei poemi possibili. Studi su Francesco Patrizi da Cherso, Roma, Bulzoni.

Boyd H. Hill (1965), "The Grain and the Spirit in Mediaeval Anatomy”, Speculum, 40 (1), pp. 63-73.

Buffet-Mecarelli, Anna-Julie (2003), "Dimensions encyclopédiques de la 'fureur' chez Francesco Patrizi da Cherso (1553-1557)", Chroniques italiennes, 2/3, pp. 109122.

Bullard, Melissa M. (1990), "The Inward Zodiac: A Development in Ficino's Thought on Astrology", Renaissance Quarterly, 43 (4), pp. 687-708.

Castelli, Patrizia (ed.) (2002), Francesco Patrizi filosofo platonico nel crepuscolo del Rinascimento, Florencia, Olshcki.

Comparato, Vittor I. (2006), Utopía. Léxico de Política, Buenos Aires, Nueva Visión.

Copenhaver, Brian (1984), "Scholastic Philosophy and Renaissance Magic in the De Vita of Marsilio Ficino", Renaissance Quarterly, XXXVII, pp. 523-549.

Curcio, C. (1941), Utopisti e riformatori sociali del Cinquecento. A. F. Doni, V. Foglietta, F. Patrizi da Cherso, L. Agostini, Bolonia, Zanichelli.

Fattori, Marta y Bianchi, Massimo L. (1984), Spiritus: IV Colloquio internazionale del Lessico intellettuale europeo, Roma, Edizioni dell'Ateneo.

Firpo, Luigi (1948), “L'utopia politica nella Controriforma”. En: Russo, Luigi (dir.), Contributi alla Storia del Concilio di Trento e della Controriforma, Quaderni di Belfagor, I, Florencia, Vallecchi, pp. 78-108.
Firpo, Luigi (1964), "Il pensiero politico del Rinascimento e della Controriforma”. En: Marzorati (dir.), Grande antologia filosofica, Milán, vol. X, pp. 179-819.

Firpo, Luigi (1975), La città ideale nel Rinascimento, Turín, UTET.

Garfagnini, Giancarlo (1986), Marsilio Ficino e il ritorno di Platone, Florencia, L. Olschki.

Garin, Eugenio (1981), El zodíaco de la vida, Barcelona, Península.

Granada, Miguel A. (1984), "Amor, spiritus, melancholia", Faventia, V (6), pp. 51-71.

Gentile, S. (1983), "In margine all'epistola 'De divino furore' di Marsilio Ficino", Rinascimento, serie II, vol. XXXIII, pp. 33-77.

Grendler, Paul F. (1965), "Utopia in Renaissance Italy: Doni's New World", Journal of the History of Ideas, 26 (4), pp. 479-483.

Grendler, Paul F. (1969), Critics of the Italian World, 1530-1560: Anton Francesco, Nicolò Franco \& Ortensio Lando, Madison, University of Wisconsin Press.

Hankins, James (1996), "Humanism and the Origins of Modern Political Thought". En: J. Kraye (ed.), The Cambridge Companion to Renaissance Humanism, Cambridge University Press, pp. 118-141.

Hirai, Hiro (2011), Medical Humanism and Natural Philosophy. Renaissance Debates on Matter, Life and the Soul, Leiden, Brill.

Hirai, Hiro (2014), "The New Astral Medicine". En: B. Dooley (ed.), A Companion to Astrology in the Renaissance, Leiden, Brill, pp. 267-286.

Huss, Bernhard (2011), "La teoria del furor poeticus come arma dottinaria: Ficino, Landino e il Cinquecento". En: J. Solervicens, La poètica renaixentista a Europa. Una recreació del llegat clàssic, Barcelona, Puntum \& Mimesi, pp. 19-46.

Jaeger, Werner (1957), "Aristotle's Use of Medicine as a Model of Method of his Ethics", Journal of Hellenistic Studies, 77 (1), pp. 54-61.

Keyt, David (1991), “Three Basic Theorems in Aristotle's Politics". En: D. Keyt and F.D. Miller, Jr. (eds.), A Companion to Aristotle's Politics, Oxford, Blackwel, pp. 118-41.

Kristeller, Paul O. (1943), The Philosophy of Marsilio Ficino, Columbia, Princeton University Press.

Kristeller, Paul O. (1978), "Philosophy and Medicine in Medieval Renaissance Italy", en Stuart F. Spicker (ed.), Organism, Medicine, and Metaphysics, Philosophy and Medicine, vol. 7, pp. 29-40

Laín Entralgo, Pedro (1982 [1970]), La medicina hipocrática, Madrid, Alianza Editorial. 
Leinkauf, Thomas. (1990), II neoplatonismo di Francesco Patrizi da Cherso come presupposto della sua critica ad Aristotele, Florencia, La Nuova Italia.

Lines, David A. (2002), Aristotle's Ethics in the Italian Renaissance (ca. 1300-1650): The Universities and the Problem of Moral Educations, Leiden, Brill.

Maier-Kaapoor, Cecilia (2010), Marsilio Ficino's MedicoPhilosophical Language of Love. Its Genesis and its Reception amongst Sixteenth-Century Italian Love Treatises, Baltimore, UMI Dissertation Services.

Miller, Fred D., Jr. (2000), "Aristotle: Naturalism". En: Ch. J. Rowe and M. Schofield (eds.), The Cambridge History of Greek and Roman Political Thought, Cambridge University Press, pp. 321-43.

Molina González, Liliana C. (2012), Fisiología y ética. Fundamentos fisiológicos de la psicología moral en Galeno de Pérgamo, Tesis de Doctorado. Universidad de Valladolid.

Moreno Chumillas, Evelio (1991), Las ciudades ideales del siglo XVI, Barcelona, Editorial Sendai.

Muccillo, Maria (1975), "La storia della filosofia presocratica nelle 'Discussiones peripateticae' di Francesco Patrizi da Cherso", La Cultura, 13, pp. 48-105.

Muccillo, M. (1981), "La vita e le opere di Aristotele nelle 'Discussiones peripateticae' di Francesco Patrizi da Cherso”, Rinascimento, ser. II, 21, pp. 53-119.

Muccillo, Maria (1986a), "Aristotelismo, Platonismo ed ermetismo ne La città felice di Francesco Patrizi da Cherso". En: G. Saccaro del Buffa ed Arthur O. Lewis (eds.), Utopie per gli anni'80, Roma, Gangemi, pp. 553-577.

Muccillo, M. (1986b), "Marsilio Ficino e Fancesco Patrizi da Cherso". En: G. C. Garfagnini (ed.), Marsilio Ficino e il ritorno di Platone, Roma, Olschki, pp. 615-679.

Piaia, Gregorio (1996), "Tra misticismo e neoplatonismo 'filosofia dei fiumi'. II tema delle acque in Francesco Patrizi", Quaderni per la storia dell'Università di Padova, XXIX, pp. 127-146.
Plastina, Sandra (1992), Gli alumni di Crono. Mito, linguaggio e storia in Francesco Patrizi da Cherso, Messina, Rubbettino Editore.

Prins, Jacomien (2009), Echoes of an Invisible World: Marsilio Ficino and Francesco Patrizi on Cosmic Order and Music Theory, Ph. D. Universidad de Utrecht.

Puliafito, Anna L. (1987), "Per uno studio della 'Nova de Universis Philosophia' di Francesco Patrizi da Cherso: note alla 'Panaugia'", Atti e memorie della Accademia toscana di scienze e lettere 'La Colombaria', 52, pp. 160-199.

Reeve, C. D. C. (2009), "The Naturalness of the Polis in Aristotle". En: G. Anagnostopoulos (ed.), A Companion to Aristotle, Oxford, Wiley-Blackwell, pp. 512-25.

Ricci, Saverio (2008), Inquisitori, censori, filosofi sullo scenario della Controriforma, Roma, Salerno.

Siraisi, Nancy (2007), History, Medicine and the Traditions of Renaissance Learning, Ann Arbor, University of Michigan.

Tafuri, Manfredo (1985), Venezia e il Rinascimento. Religione, scienza, architettura, Roma, Einaudi.

Vasoli, Cesare (1981), “Aristotele e i 'filosofi antiquiores' nelle 'Discussiones Peripateticae' di F. Patrizi", Atti e memorie dell'Accademia Petrarca di lettere, arti e scienze, n.s. (44), pp. 205-233.

Vasoli, Cesare (1989), Francesco Patrizi da Cherso, Roma, Bulzoni.

Vasoli, Cesare (1996), "La critica di Francesco Patrizi ai 'principia' aristotelici”, Rivista di storia della filosofia, 51, pp. 713-787.

Verbeke, Gerard (1945), L'evolution de la doctrine du pneuma, du stoicisme à S. Agustin, París, D. De Brower.

Walker, D. P. (1958), "The Astral Body in Renaissance Medicine", Journal of the Warburg and Courtauld Institutes, 21, (1/2), pp. 119-133.

Walker, D. P. (2000 [1958]), Spiritual and Demonic Magic from Ficino to Campanella, University Park, Pennsylvania State University Press. 